\section{Apparent Tolerance to Huanglongbing in Citrus and Citrus-related Germplasm}

\author{
Godfrey P. Miles and Ed Stover ${ }^{\mathbf{1}}$ \\ U.S. Horticultural Research Laboratory, U.S. Department of Agriculture, \\ Agricultural Research Service, 2001 South Rock Road, Fort Pierce, FL 34945
}

Chandrika Ramadugu

University of California, Riverside, CA 92521

Manjunath L. Keremane and Richard F. Lee

U.S. Department of Agriculture, Agricultural Research Service, National Clonal Germplasm Repository for Citrus and Dates, Riverside, CA 92507

Additional index words. asian citrus psyllid, Aurantioideae, citron, citrus breeding, citrus greening, Rutaceae

\begin{abstract}
In a Fort Pierce, FL, field planting, plant growth, and Huanglongbing (HLB) severity were assessed as indicators of HLB tolerance on progenies of 83 seed-source accessions of Citrus and Citrus relatives mainly from the Riverside, CA, genebank. The HLB-associated pathogen [Candidatus Liberibacter asiaticus ( $C$ Las)] and vector [asian citrus psyllid (ACP), Diaphorina citri] were abundant, and trees were naturally challenged for 6 years before metrics (leaf mottle, percent canopy mottle, overall health, canopy density, canopy width, canopy height, and trunk diameter) were collected in Oct. and Nov. 2015. The healthiest trees with low or no HLB symptoms were distant citrus relatives: Balsamocitrus dawei, Bergera koenigii, Casimiroa edulis, Clausena excavata, Murraya paniculata, and one accession of Severinia buxifolia. Within Citrus, most of the healthiest trees with densest canopies, little leaf loss, and greater growth were those with pedigrees that included Citrus medica (citron). These included progenies of Citrus hybrid ('Limon Real'), Citrus limetta, Citrus limettioides, Citrus limonia, C. medica, Citrus volkameriana, and some Citrus limon accessions. Trees in this category exhibited distinct leaf-mottle characteristic of HLB and substantial pathogen titers, but maintained dense canopies and exhibited good growth. Trees from seed-source accessions in the genus Citrus without citron in their background were generally among the least healthy overall with less dense canopies. The exceptions were progenies of two Citrus aurantium accessions, which were markedly healthier than progenies of other Citrus seed-source accessions not derived from citron. Linear regression analysis, between metrics collected and pedigree of seed parent, indicated that percentage of citron in the pedigree significantly correlated with measures of tolerance. Although no commercial Citrus genotypes yielded progenies with strong HLB resistance, in this field experiment several progenies maintained dense canopies and good growth, and may be useful for breeding HLB tolerant cultivars.
\end{abstract}

HLB is a highly destructive disease of Citrus associated with the fastidious gramnegative, obligate-parasite, phloem-limited $\alpha-$ Proteobacteria, Candidatus Liberibacter

Received for publication 22 Sept. 2016. Accepted for publication 27 Oct. 2016.

This research was originally presented at the 2016 annual meeting of the Florida State Horticultural Society.

We thank Sean Reif, Patrick Zagorski, Megan Geraghty, Ellen Cochrane, Jennifer Wildonger, and Steve Mayo for their technical assistance in this project which was financially supported by Citrus Research and Development Foundation project 15-025 and USDA Agricultural Research Service project, 6618-21000-014-00.

Mention of trade names or commercial products is solely for the purpose of providing specific information and does not imply recommendation or endorsement by the U.S. Department of Agriculture. USDA is an equal opportunity provider and employer. ${ }^{1}$ Corresponding author. E-mail: ed.stover@ars. usda.gov. regions in the United States and worldwide. Presently, greater than $80 \%$ of Florida citrus trees are infected with CLas (Singerman and Useche, 2015) with the great majority exhibiting associated disease symptoms: yellow asymmetrical patterns (blotchy mottle) on leaves, vein yellowing and thickening, thinning canopies, dieback, increased fruit drop, and a measurable decline in fruit quality. At the anatomical level, HLB induces progressive degeneration of the phloem tissue resulting in partial or complete collapse of the phloem with concomitant callose plugging of lateral pits and sieve plates (Achor et al., 2010; Chen et al., 2016; Folimonova and Achor, 2010; Koh et al., 2012; Schneider, 1968). In roughly a decade, the Florida citrus industry has experienced a decline in crop production of more than $50 \%$ (USDA National Agricultural Statistics Service, 2015).

The U.S. citrus industry, as with the rest of the world, primarily relies on cultivars with a very narrow genetic base. The most important commercial cultivars, excluding lemons and limes, are the product of only two parental species: Citrus reticulata and Citrus maxima. Additionally, sweet orange, which is among the most broadly cultivated tree fruits in the world, possesses little genetic variation despite having a diverse array of desirable phenotypic traits (Curk et al., 2016; Gulsen and Roose, 2001; Matsumoto and Magano, 2013; Novelli et al., 2006). With the world's citrus production at risk of collapse, identifying resistance and tolerance to HLB is important to understanding this pathosystem, and cultivars that tolerate HLB are needed to sustain the citrus industry.

Resistance in citrus relatives has only been observed in genera not widely classified as Citrus (Ramadugu et al., 2016), which may offer valuable genetic diversity for tolerance to HLB as well as other Citrus diseases. Wild Citrus species are increasingly threatened worldwide and it is crucial to make efforts to conserve these resources, which may be vitally important for future Citrus cultivar improvement (Malik et al., 2013). Though true resistance to HLB is the ultimate goal, tolerance to HLB may be invaluable for short-term survival of the citrus industry both here in the United States and abroad. A number of HLB-tolerant cultivars have been reported by research groups around the world (Koizumi et al., 1993; Ramadugu et al., 2016; Shokrollah et al., 2009; Stover and McCollum, 2011; Stover et al., 2014). Knowledge of the genetics underlying resistance and tolerance to HLB, from both Citrus and Citrus relatives, may be useful for conventional and biotechnology-based breeding. Further work is needed to assess this potential and to realize its commercial value by mobilizing resistance and tolerance into the range of commercial fruit types necessary to satisfy consumer demands. The objective of this study was to evaluate growth and visible disease severity metrics on progenies of 83 diverse seed-source accessions of Citrus and Citrus relatives in a Florida field planting to identify their relative tolerance to HLB. 


\section{Materials and Methods}

Plant source materials and experimental design. Seeds, representing a broad crosssection of diversity in Citrus and Citrus relatives, were acquired from the USDAARS National Clonal Germplasm Repository for Citrus and Dates at the University of California (UCR), Riverside, CA (http:// www.citrusvariety.ucr.edu). Seeds used for this study were collected from 124 accessions of Citrus and Citrus relatives, mainly of the subfamily Aurantioideae, family Rutaceae, representing $\approx 85 \%$ of the genetic diversity within the UCR collection (Barkley, 2003). Good germination was obtained from about 100 accessions, generating $\approx 886$ seedlings. Information on the phylogenetic relationships of the seed-source genotypes used for this study, are described in Barkley (2003) and Bayer et al. (2009). Seeds of Zanthoxylum ailanthoides (subfamily Toddalioideae) were secured from the University of Georgia. Seeds of Casimiroa edulis (subfamily Toddalioideae), Afraegle paniculata and Aegle marmelos (subfamily Aurantioideae) were obtained from the Fruit and Spice Park (Miami-Dade County, FL).

Progeny growth and development, field planting, and general care and maintenance were described in Richardson et al. (2011) and Westbrook et al. (2011) and were consistent with citrus production practices for processing before HLB. Briefly, seeds were germinated in individual plastic cells (Conetainers $^{\mathrm{TM}}$, Stuewe and Sons Inc., Tangent, $\mathrm{OR}$ ) and grown under greenhouse conditions at the USDA-ARS U.S. Horticultural Research Laboratory in Fort Pierce, FL. Six-to-ninemonth-old seedlings, eight single-plant replicates for each seed parent, were planted at the USDA-ARS, Fort Pierce, FL, farm during June and July 2009. A randomized complete block design was used with $0.6 \mathrm{~m}$ spacing within rows and there was $3.5 \mathrm{~m}$ between rows. The planting was irrigated regularly using micro sprinklers and fertilized using a regime similar to that of a new commercial planting of Citrus. To maintain high ACP pressure and maximize challenge by $C$ Las, no insecticides were applied, and high ACP populations were apparent year round.

Growth measurements. Tree height, canopy width, tree canopy volume (TCV), trunk diameter, canopy density, overall health, and HLB phenotypic leaf symptoms (mottle, and $\%$ mottle) were assessed during 2 weeks from late Oct. through early Nov. 2015. Tree height was measured using a Crain measuring ruler (model CMR-25; Mound City, IL), and tree canopy width was measured on an east/west and north/south plane. TCV was calculated on the assumption that tree shape was one-half a prolate spheroid (TCV $=4 \pi / 6 \times$ $\mathrm{H} \times \mathrm{W} 1 \times \mathrm{W} 2$ ). Trunk diameter was measured $10 \mathrm{~cm}$ above the soil line.

Disease severity assessment. For scoring of disease severity metrics, a five-point scale was used where five is worst and one is fully healthy (devoid of visible disease symptoms), at a half point resolution. Subjective assessments of trees were conducted by two people to reach a consensus score.

Scoring for leaf mottle was based on the presence of yellow asymmetrical patterns (blotchy mottle) using the following scale: 1 = no visible degree of mottling; 2 = light leaf mottling; 3 = moderate level of leaf mottling; $4=$ heavy leaf mottling; $5=$ severe leaf mottling. The percentage of the entire canopy leaf surface mottled on each tree was also estimated. Leaves affected by other visible stresses causing leaf yellowing (e.g., canker and leaf miners) were excluded. Canopy density was based on visually inspecting the tree canopy from all quadrants to determine an overall score. Scoring was as follows: 1 = completely healthy, dense canopy; 2 = light canopy thinning; 3 = moderate canopy thinning; 4 = heavy canopy thinning; $5=$ worst case canopy thinning - most branches devoid of leaves. Scoring for dieback was determined as follows: $1=$ completely healthy, no observed dieback; $2=$ a single medium-to-large branch with some level of dieback; 3 = multiple small, medium or large branches, three to four branches total, exhibiting some level of dieback; $4=$ heavy dieback, four to five branches of medium to large size showing some level of dieback; $5=$ worst case trees with five or more branches (medium-to-large) with dieback. The scoring for overall health was as follows: $1=$ completely healthy, no signs of disease; 2 = very good health; 3 = moderate/average health; $4=$ poor health; $5=$ worst case health, many of which were near death.

Statistical analysis. Means and standard deviations were calculated using Excel (version 2013; Microsoft, Redmond, WA). Regression analyses of several data sets were conducted (also with Excel) to assess relationships between measures of HLB tolerance and estimated pedigree percentages for each seed parent (pedigrees were not determined for individual seedlings) from each of the progenitor Citrus species that gave rise to all cultivated citrus: citron (C. medica), pummelo (C. maxima), mandarin (C. reticulata), and papeda (C. micrantha or related species). The pedigree estimates vary in confidence with some based on recently published genomic sequence analyses (Curk et al., 2016) and others on published speculation based on morphology (Hodgson, 1967). Relationships are indicated as positive when health increases with increasing percentage of the indicated progenitor species in the seed-source accession pedigree.

\section{Results and Discussion}

In this study, growth and disease severity metrics were evaluated on progenies of 83 diverse seed-source genotypes of Citrus and Citrus relatives in a Florida field planting to identify the relative tolerance to HLB under natural conditions. This field trial was established in 2009 and conducted in an HLB-endemic region with year-round ACP pressure. Data were collected over 2 weeks in the autumn (from late Oct. through Nov. 2015), when CLas titer and symptoms are the highest in Florida (Manjunath et al., 2008; Wang et al., 2006). Initial infection with CLas and development of HLB symptoms is not uniform. After 6 years, the interaction between the pathogen and each host tree is well established with only gradual subsequent changes, and the effects on growth essentially reflect an integration of the disease response over the planting life. Therefore, the data we collected at this single time point is ideal for assessing the cumulative response to HLB. For this present study, $C$ Las titer data from Ramadugu et al. (2016) are provided as a reference, and the 2015 data $C$ Las titer data were collected within 2 weeks of our data collection.

Nucellar embryony varies significantly within the Rutaceae (Frost and Soost, 1968); consequently, the progenies employed for this study were either genetically identical to the maternal parent (seeds serving as clonal propagules) or half-sib hybrids with only the seed parent known. Therefore, only the seed parent is known for this material and all discussions are based on the seed-source accessions for each tree in the study. For progeny of each seed-source accession, growth measurements (TCV and trunk diameter), and disease severity metrics (leaf mottle, percent canopy mottle, overall health, canopy density, and dieback) are summarized in Table 1 along with accession pedigrees and CLas titer levels as Ct from qPCR (5-year mean and levels for 2015; from Ramadugu et al., 2016). It is important to note that $\mathrm{Ct}$ is inversely related to CLas titer. Data on fruit were not collected because only a small proportion of trees were cropping and in these young trees, differences were influenced by the relative precocity of the genotypes tested.

Progeny of seed-source accessions outside the genus Citrus were among the healthiest and many of these have been shown to have substantial resistance to HLB with little or no CLas detectable (Ramadugu et al., 2016; Table 1). Across all metrics, except for leaf-mottle severity and percent mottle, progeny of many Citrus seed-source accessions with citron in their pedigree outperformed other Citrus.

Overall health. Citrus with citron in their pedigree generally had an overall health score similar to trees outside the genus Citrus, both near moderate/average, whereas Citrus without citron in their pedigree generally scored a rating of poor (Table 1). The healthiest progeny group for Citrus with citron in the pedigree was from 'Volkamer' lemon hybrid (CRC 3050) with a mean of 2.2 (very good/good health). However, this overall health score was similar to that of 'Olivelands' sour orange (CRC 2717) progeny, the healthiest Citrus without citron in pedigree, with an overall health score of 2.3 (very good/good health) (Table 1). In a recent publication looking at HLB and bacterial titer levels for these same trees over 6 years (Ramadugu et al., 2016), it was shown that all trees in the genus Citrus had substantial 


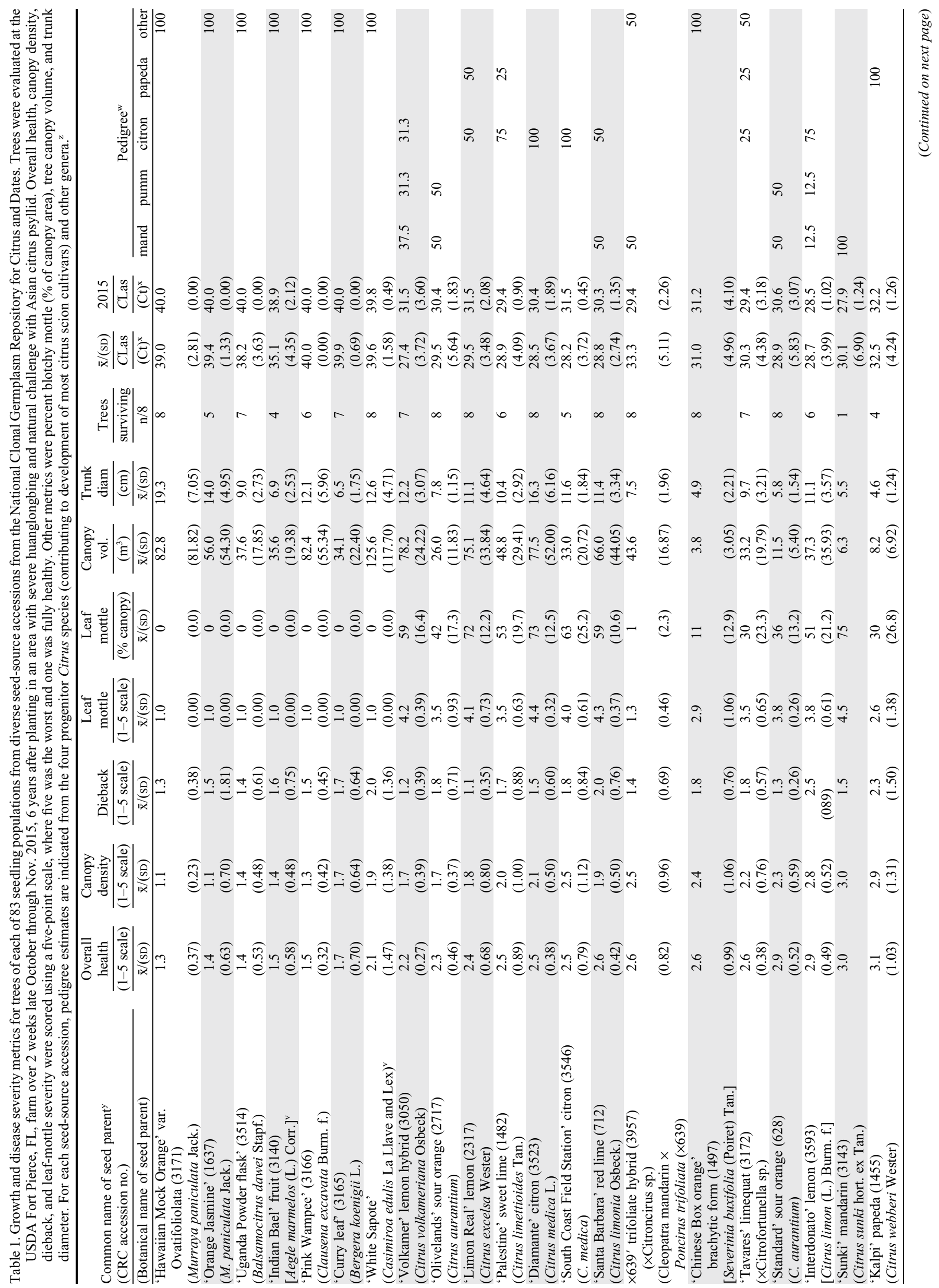




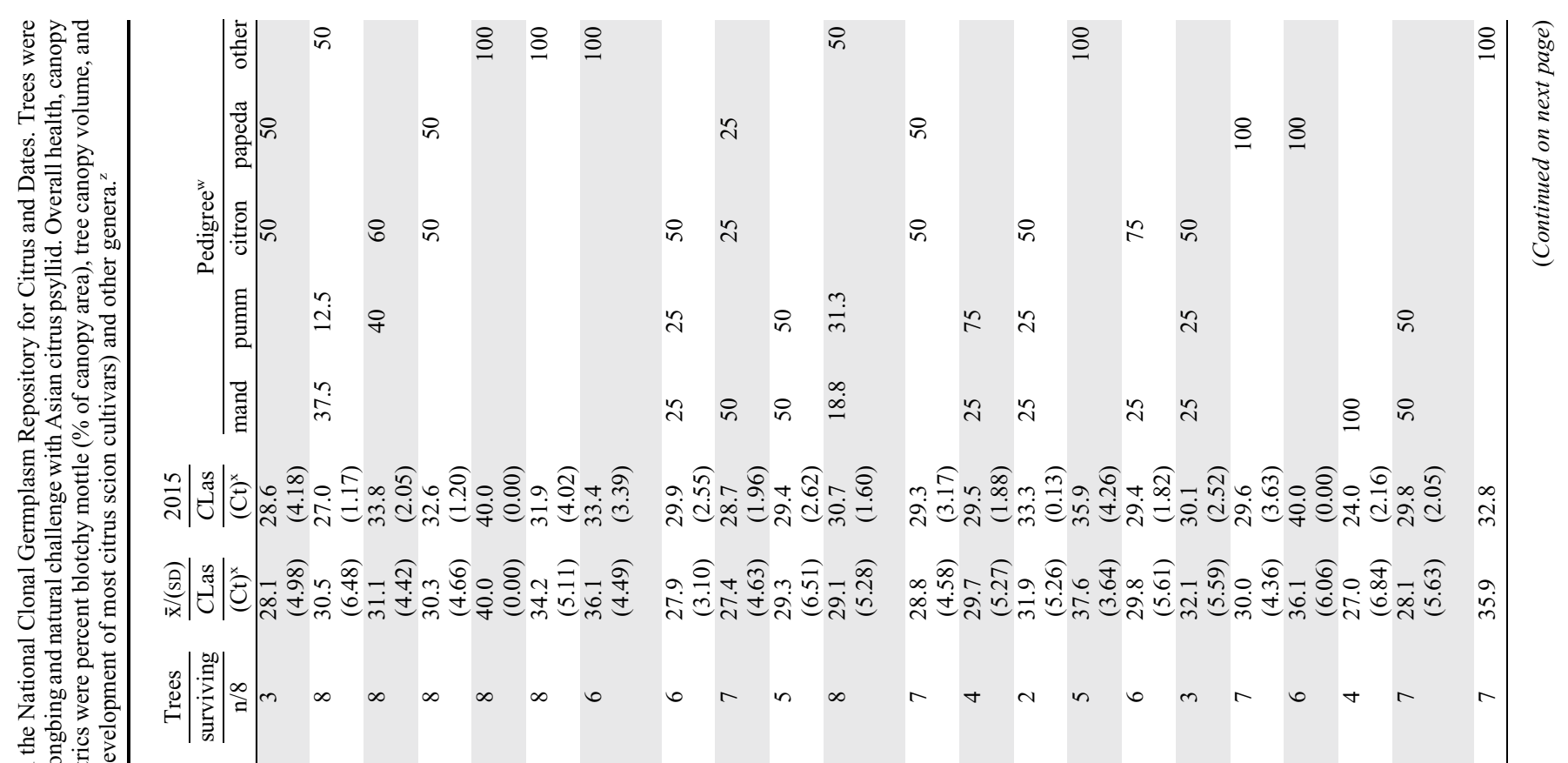

듬웜

壱离

옹

ठ 己े

跣

总

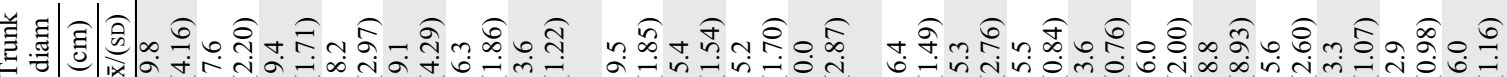

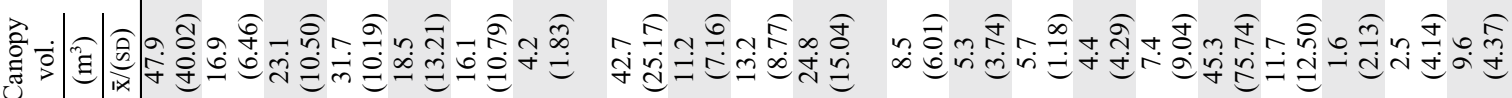

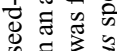

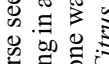

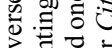

츨 吾

¿

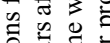

焉焉

잉

응

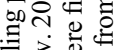

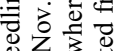

क 50 얼

论

过 节

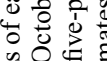

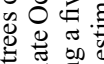

훈

号芯司

宁

它造.

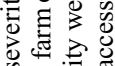

की

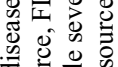

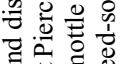

है

考宁志

㝋会吾

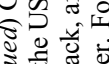

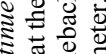

츙

记总

远要普

용

๘ँ

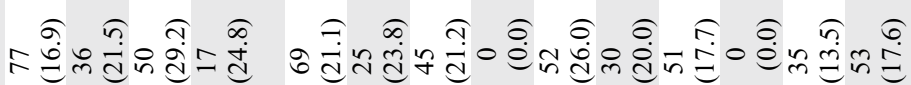

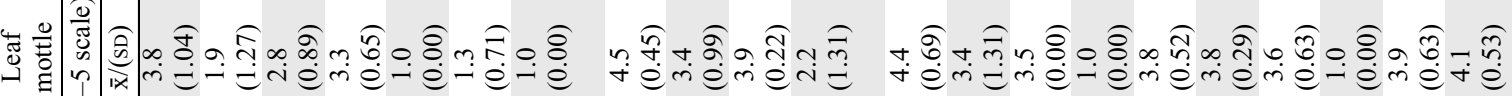

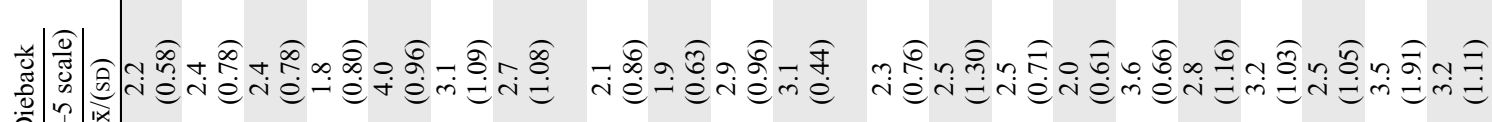

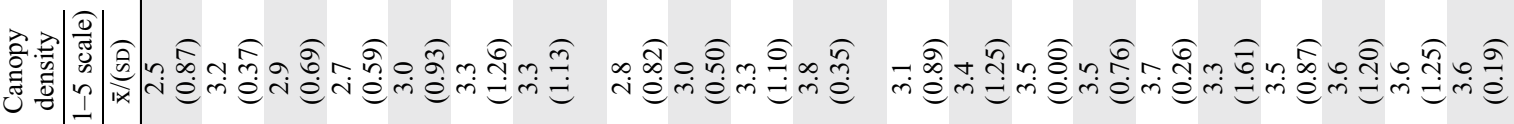

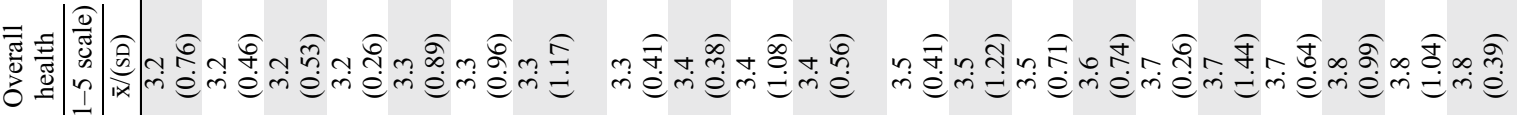

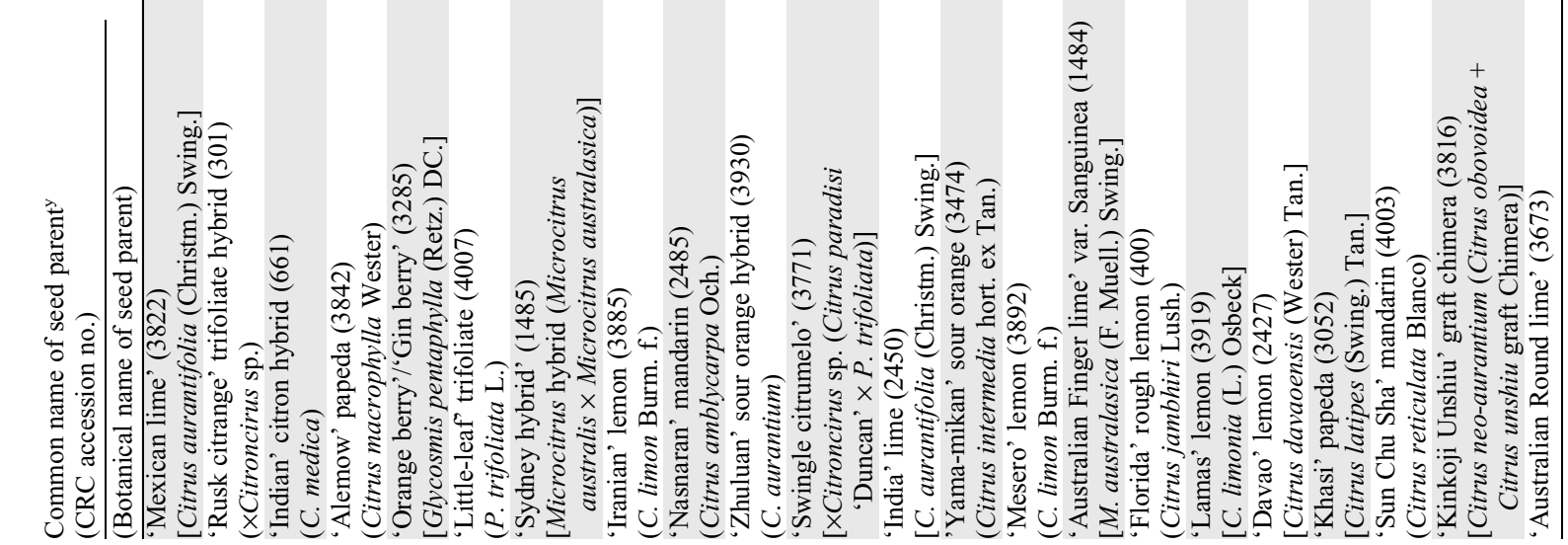




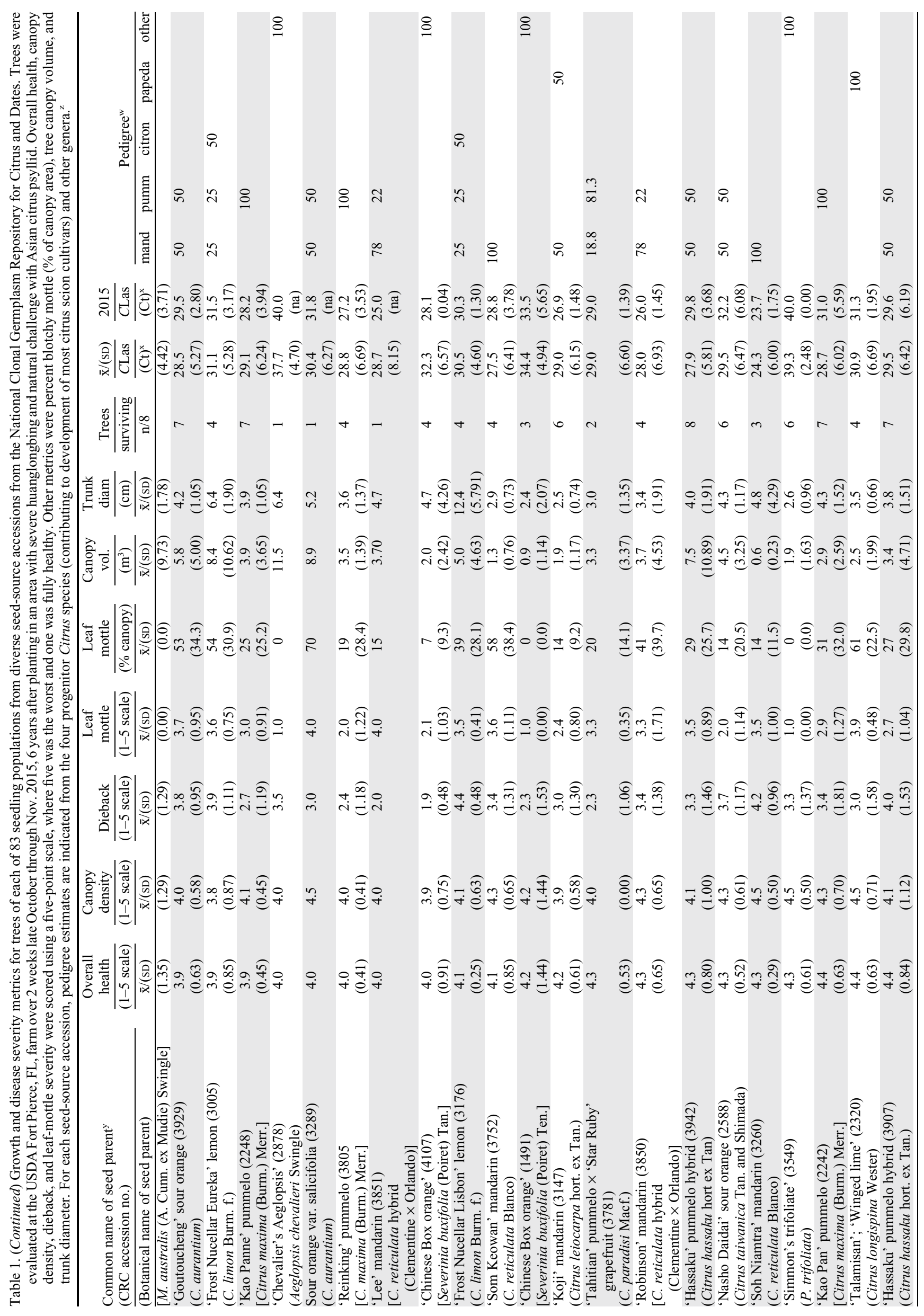




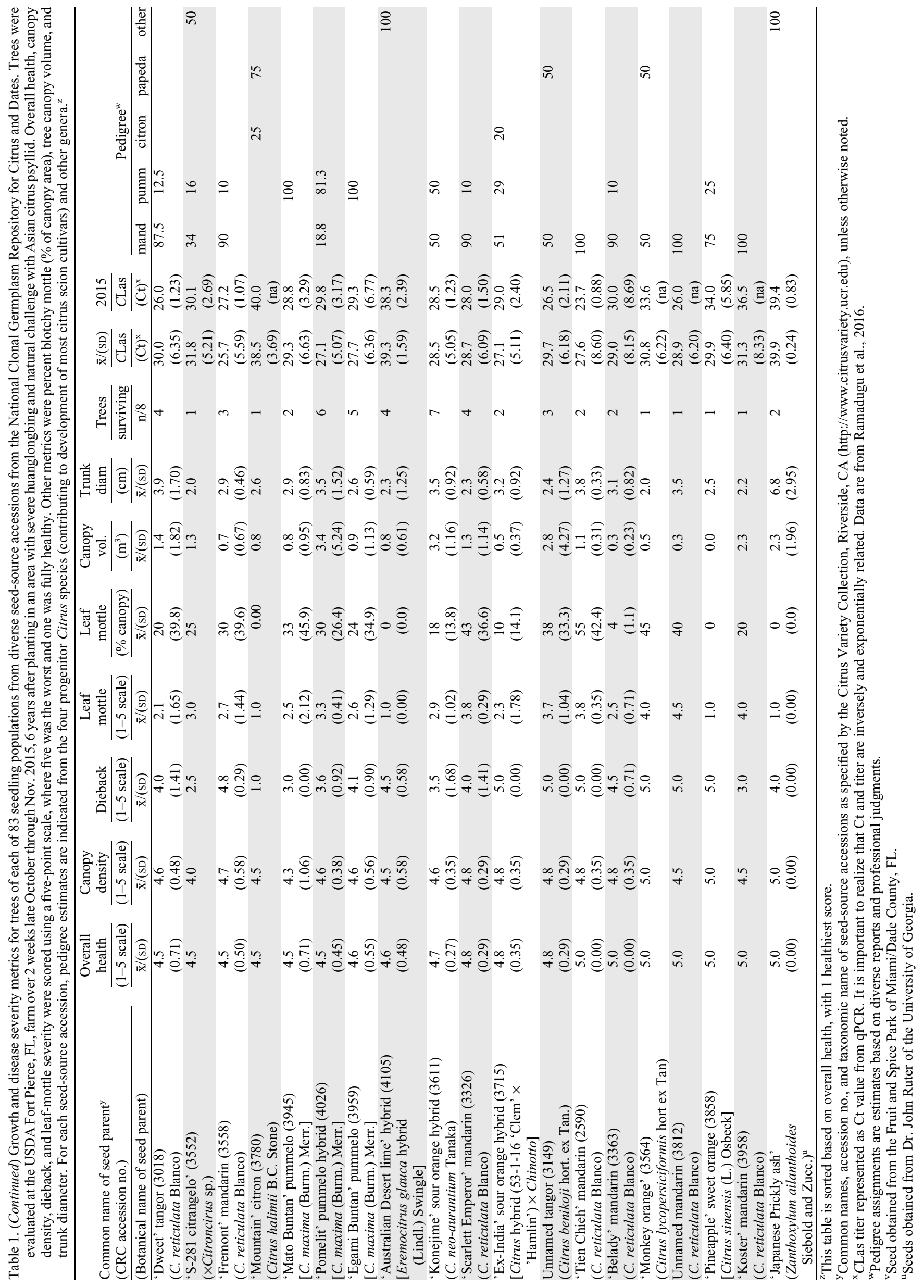


Table 2. Seedling populations from 83 diverse seed-source accessions (from the National Clonal Germplasm Repository for Citrus and Dates) were planted at the USDA Fort Pierce, FL Farm. Trees were evaluated (2 weeks October through Nov. 2015) 6 years after planting with continuous exposure to high populations of Asian citrus psyllid and severe huanglongbing pressure. Data in this table are for progenies of the seed-source accessions considered to have $100 \%$ of their pedigree from one of the four progenitor species contributing to development of most citrus scion cultivars. Where noted, disease severity metrics were scored using a five-point scale, where five is the worst and one is fully healthy.

\begin{tabular}{|c|c|c|c|c|c|c|c|}
\hline $\begin{array}{l}\text { Species: Common name of seed parent }{ }^{2} \\
\text { (accession no.) }\end{array}$ & $\begin{array}{l}\text { Overall health } \\
\text { (1-5 scale) }\end{array}$ & $\begin{array}{l}\text { Canopy density } \\
(1-5 \text { scale })\end{array}$ & $\begin{array}{l}\text { Dieback } \\
(1-5 \text { scale })\end{array}$ & $\begin{array}{l}\text { Leaf mottle } \\
(1-5 \text { scale })\end{array}$ & $\begin{array}{l}\text { Leaf mottle } \\
\text { (\% of canopy) }\end{array}$ & $\begin{array}{l}\text { Canopy } \\
\text { vol. }\left(\mathrm{m}^{3}\right)\end{array}$ & $\begin{array}{c}\text { Trunk } \\
\text { diam. }(\mathrm{cm})\end{array}$ \\
\hline $\begin{array}{l}\text { Soh Niamtra' (CRC 3260), 'Som Keowan' } \\
\text { (CRC 3752) }\end{array}$ & $4.2^{\mathrm{x}}$ & 4.2 & 3.7 & 3.8 & 41 & 1.7 & 3.5 \\
\hline $\begin{array}{l}\text { Unnamed (CRC 3812), 'Koster' (CRC 3958), } \\
\text { 'Sun Chu Sha' (CRC 4003) }\end{array}$ & $(0.83)$ & $(1.64)$ & $(1.39)$ & $(0.75)$ & $(28.8)$ & $(2.00)$ & $(2.62)$ \\
\hline \multicolumn{8}{|l|}{$\begin{array}{l}\text { Pummelo: 'Kao Pan' (CRC 2242), 'Kao Panne' } \\
\text { (CRC 2248), }\end{array}$} \\
\hline 'Egami Buntan’ (CRC 3959) & $(0.55)$ & $(0.57)$ & $(1.33)$ & $(1.18)$ & $(28.2)$ & $(2.61)$ & $(1.22)$ \\
\hline $\begin{array}{l}\text { Citron: 'Diamante' (CRC 3523), } \\
\text { 'South Coast Field Station' (CRC 3546) }\end{array}$ & $\begin{array}{l}2.5 \\
(0.54)\end{array}$ & $\begin{array}{l}2.2 \\
(0.78)\end{array}$ & $\begin{array}{l}2.0 \\
(0.68)\end{array}$ & $\begin{array}{l}4.3 \\
(0.46)\end{array}$ & $\begin{array}{c}69 \\
(18.1)\end{array}$ & $\begin{array}{l}60.4 \\
(45.33)\end{array}$ & $\begin{array}{l}14.6 \\
(5.34)\end{array}$ \\
\hline $\begin{array}{l}\text { Papeda: 'Kalpi' (CRC 1455), 'Talamisan' } \\
\text { (CRC 2320), }\end{array}$ & 3.7 & 3.6 & 2.8 & 2.7 & 35 & 6.4 & 4.4 \\
\hline
\end{tabular}

Table 3. Regressions of growth and health metrics versus pedigree percentage from each progenitor "true" Citrus species. Data are for trees of 83 seedling populations from diverse seed-source accessions from the National Clonal Germplasm Repository for Citrus and Dates. Growth measurements and disease severity metrics were evaluated at the USDA Fort Pierce, FL, farm over two weeks late October through Nov. 2015, 6 years after planting in an area with severe huanglongbing and natural challenge with Asian citrus psyllid. Overall health, canopy density, dieback, and leaf-mottle severity were scored using a five-point scale, where five was the worst and one was fully healthy. Other metrics were percent blotchy mottle (\% of canopy area), tree canopy volume $\left(\mathrm{m}^{3}\right)$, and trunk diameter. The slope indicates a positive relationship when increased health or growth is associated with increased pedigree percentage of indicated progenitor species.

\begin{tabular}{|c|c|c|c|c|c|c|}
\hline \multirow[b]{2}{*}{ Metric } & \multicolumn{3}{|c|}{ Citron $\%$ in pedigree } & \multicolumn{3}{|c|}{ Mandarin $\%$ in pedigree } \\
\hline & $r^{2}$ & $P$ value & Slope & $r^{2}$ & $P$ value & Slope \\
\hline Leaf mottle (1-5) & 0.112 & 0.006 & + & 0.020 & 0.251 & + \\
\hline Leaf mottle (\%) & 0.200 & $2.00 \mathrm{E}^{-04}$ & + & 0.005 & 0.586 & - \\
\hline Overall health $(1-5)$ & 0.296 & $3.00 \mathrm{E}^{-06}$ & + & 0.169 & $7.00 \mathrm{E}^{-04}$ & - \\
\hline Canopy density (1-5) & 0.317 & $1.00 \mathrm{E}^{-06}$ & + & 0.161 & $9.00 \mathrm{E}^{-04}$ & - \\
\hline Dieback $(1-5)$ & 0.143 & 0.002 & + & 0.219 & $8.00 \mathrm{E}^{-05}$ & - \\
\hline Canopy volume $\left(\mathrm{m}^{3}\right)$ & 0.423 & $5.00 \mathrm{E}^{-09}$ & + & 0.150 & 0.001 & - \\
\hline \multirow[t]{2}{*}{ Trunk diameter $(\mathrm{cm})$} & 0.570 & $2.00 \mathrm{E}^{-13}$ & + & 0.163 & $8.00 \mathrm{E}^{-04}$ & - \\
\hline & \multicolumn{3}{|c|}{ Pummelo $\%$ in pedigree } & \multicolumn{3}{|c|}{ Papeda \% in pedigree } \\
\hline Leaf mottle (1-5) & 0.019 & 0.279 & - & 0.007 & 0.519 & - \\
\hline Leaf mottle $(\%)$ & 0.028 & 0.187 & - & 0.004 & 0.619 & + \\
\hline Overall health $(1-5)$ & 0.025 & 0.208 & - & 0.008 & 0.476 & + \\
\hline Canopy density (1-5) & 0.036 & 0.132 & - & 0.016 & 0.317 & + \\
\hline Dieback (1-5) & 0.004 & 0.647 & - & 0.038 & 0.120 & + \\
\hline Canopy volume $\left(\mathrm{m}^{3}\right)$ & 0.065 & 0.041 & - & 0.008 & 0.477 & + \\
\hline Trunk diameter $(\mathrm{cm})$ & 0.037 & 0.123 & - & 0.002 & 0.756 & - \\
\hline
\end{tabular}

CLas titer. Interestingly, even the healthiest progenies of Citrus seed-source accessions had high titer levels throughout the 6-year field trial, and health in the presence of high pathogen is indicative of HLB tolerance.

Although trees from genera other than Citrus had healthier trees on average compared with Citrus, they were not all healthy. The least healthy progenies from other genera were from seed-source accessions 'Japanese Prickly ash', 'Australian Desert lime' hybrid (CRC 4105), 'Chevalier's Aeglopsis' (CRC 2878), 'Gin Berry' (CRC 3285), and two 'Chinese Box Orange' (CRC 1491 and 4107). It should be noted that trees from these seed-source accessions, except for the two trees having canopy volumes $20 \%$ to $40 \%$ of mandarin trees (R. Krueger, personal communication). In this study, canopy volumes of "pure" citron populations averaged 35fold greater than the "pure" mandarin and 20 -fold greater than the "pure" pummelo populations (Table 2).

$H L B$ leaf-mottle metrics. It is interesting that even the healthiest progenies of Citrus with citron in their pedigree had relatively high levels of leaf blotchy mottle (percent canopy) as well as leaf-mottle severity. This seems contradictory, however, it was also reported in a recent study that the most HLBtolerant mandarin hybrids displayed the greatest degree of HLB mottling (Stover et al., 2016). With respect to citrus relatives not in the genus Citrus, the only leaf mottle observed was in two Chinese box orange accessions (Severinia buxifolia, CRC 1497 and CRC 4107). Both accessions carried high $C$ Las titer levels throughout the field trial for this planting (Ramadugu et al., 2016).

Data on progeny populations from accessions considered pure species. When comparing progeny populations from accessions of "pure" progenitor Citrus species, the most marked difference was TCV, where citron had an average canopy volume of $60.4 \mathrm{~m}^{3}$ compared with that of mandarin $\left(1.7 \mathrm{~m}^{3}\right)$, pummelo $\left(2.8 \mathrm{~m}^{3}\right)$, and papeda $\left(6.4 \mathrm{~m}^{3}\right)$. In addition, means for overall health, canopy density, and trunk diameter for citron were superior to mandarin, pummelo, and papeda (Table 2). Although only two pure citron seed-source accessions are represented by the data, it is interesting that these trees had good growth, dense canopies, and dramatically larger canopy volumes, but also presented high percentages of leaf mottle.

Regressions between parameters. For each seed-source accession, we estimated percent of pedigree from each of the progenitor "true" Citrus species, which have 
interbred to form all other Citrus: $C$. medica (citron), C. maxima (pummelo), C. reticulata (mandarin), and papeda (C. micrantha or similar species). It is important to emphasize that we did not genotype each tree in the planting, and the pedigrees used in analyses are solely those of the seed-source accessions. The growth and health data for individual trees were analyzed in separate regressions (Table 3 ) against the percentage of each progenitor citrus species in the pedigrees for each tree's seed-source accession. Progenies of seed-source accessions not in the genus Citrus, which largely showed little effect from HLB, were excluded from regression analyses.

Across all metrics tested, except leaf mottle, percentage pedigree of seed-source accessions derived from citron displayed a more favorable relationship to HLB tolerance than pedigree percentages of other progenitor species. Regressions between overall health and canopy density vs. percentage citron in pedigree gave moderate $r^{2}$ values $(0.296$ and 0.317$)$ and were highly significant $\left(P=3.00 \mathrm{E}^{-06}\right.$ and $1.00 \mathrm{E}^{-06}$, respectively) and positively correlated. The regressions for overall health and canopy density vs. mandarin in the pedigree gave very weak $r^{2}$ values of 0.169 and 0.161 , though accompanied by highly significant $P$ values $\left(7.00 \mathrm{E}^{-04}\right.$ and $9.00 \mathrm{E}^{-04}$, respectively), and the relationship was negative in both cases. There was no statistically significant relationship between overall health and canopy volume for either pummelo or papeda.

Regressions for growth metrics (canopy volume and trunk diameter) against percent of individual progenitor species in seedsource accession pedigrees gave the most striking differences. TCV vs. percentage citron in pedigree was highly significant $\left(P=5.00 \mathrm{E}^{-09}\right)$ with an $r^{2}=0.423$ and a positive relationship. Regression for trunk diameter vs. percentage citron in seed parent pedigree was also highly significant $(P=$ $2.00 \mathrm{E}^{-13}$ ) with an $r^{2}=0.570$ and a positive correlation. Greater trunk diameter and canopy volume are generally associated with healthy trees suggesting citron in a tree's pedigree enhances the ability to modulate and use photosynthate despite stresses associated with HLB. Across all other metrics vs. pummelo and papeda, no significant relationship was observed for either canopy volume or trunk diameter (Table 3 ).

Interestingly, regression of percent leaf mottle vs. percentage citron in pedigree was also highly significant $\left(P=2.0 \mathrm{E}^{-04} ; r^{2}=\right.$ 0.200 ) and positively correlated. No significant relationship was observed for progenies of seed-source accessions without a citron background. The ability of citrus trees to display high HLB leaf mottle, but still maintain phloem transport was demonstrated by Fan et al. (2012). In that study, even though both cultivars displayed callose deposition in sieve elements and phloem cell collapse, relatively HLB tolerant 'Florida rough lemon' (Citrus jambhiri) maintained better phloem transport than HLB sensitive sweet orange. The ability to maintain good phloem transport with extensive CLas titer is likely critical to good HLB tolerance.

\section{Conclusions}

In summary, the objective of this study was to assess growth and visible disease severity metrics on progenies of 83 seedsource genotypes of Citrus and Citrus relatives to ascertain their relative tolerance to HLB. The healthiest trees with low or absent HLB symptoms were distant relatives across all metrics except for TCV and trunk diameter (where Citrus with citron in the pedigree performed better). Within Citrus, the majority of the healthiest trees (greater trunk diameter, less branch dieback, densest canopies, and largest canopy volume) were those with pedigrees that included $C$. medica. It is noteworthy that these trees all had substantial titers of $C$ Las (Table 1) and therefore their relative health reflects tolerance rather than resistance to HLB. Trees from Citrus seed-source accessions without citron in their background were generally the least healthy overall with less dense canopies, more branch dieback, smaller trunk diameters, and dramatically smaller TCV. The exceptions were progenies of two $C$. aurantium accessions that were significantly healthier than all other trees from Citrus without citron in pedigree.

Reports of tolerance to HLB are likely greatly influenced by the growing conditions and specific comparisons to other plant material. 'Florida rough lemon' has been widely reported as HLB tolerant (Fan et al., 2012). Though it fared markedly better than the mandarins and sweet orange in this study, 'Florida rough lemon' ranked 16th out of 21 citron-derived seed-source accession progenies for overall health. Since rough lemon is highly apomictic the materials are likely the same in the two studies. Though true resistance to HLB is the ultimate goal, tolerance to HLB may be invaluable for shortterm survival of the industry both here in the United States and abroad. We propose HLB tolerance means infected trees are able to grow, maintain relatively full canopies, and ultimately in commercial scions produce fruit of acceptable quality and quantity to be profitable. Results from this study may ultimately contribute to: 1) identifying HLB-tolerant molecular markers from citron and incorporating into other market phenotypes through conventional breeding; 2) using biotechnology to implement citron-derived HLB-tolerance; and 3) encourage breeding of HLB-tolerant acid citrus fruit (lemon or lime-like phenotypes) for good quality and adaptation to regions with high HLB pressure.

\section{Literature Cited}

Achor, D., E. Etxeberria, W. Wang, S.Y. Folimonova, K.R. Chung, and L.G. Albrigo. 2010. Sequence of anatomical symptoms in citrus affected with HLB disease. Plant Pathol. J. 9:56-64.

Barkley, N.A. 2003. Genetic diversity in a citrus germplasm collection characterized with simple sequence repeat markers. $\mathrm{PhD}$ thesis. University of California, Riverside, CA.

Bayer, R.J., D.J. Mabberley, C. Morton, C.H. Miller, I.K. Sharma, P. Pfeil, S. Rich, R. Hitchcock, and S. Sykes. 2009. A molecular phylogeny of the orange subfamily (Rutaceae: Aurantioideae) using nine cpDNA sequences. Amer. J. Bot. 96:668-685.

Bové, J.M. 2006. Huanglongbing: A destructive, newly-emerging, century-old disease of citrus. J. Plant Pathol. 88:7-37.

Chen, Q. 1943. A report of a study on yellow shoot disease of citrus in Chaoshan. New Agr. Qrtly. Bul. 3:142-175.

Chen, H., G. McCollum, E. Baldwin, and J. Bai. 2016. Impacts of huanglongbing symptom severity on fruit detachment force and mechanical properties of sweet oranges (Citrus sinensis). HortScience 51:356-361.

Curk, F., F. Ollitrault, A. Gacia-Lor, F. Luro, L. Navarro, and P. Ollitrault. 2016. Phylogenetic origin of limes and lemons revealed by cytoplasmic and nuclear markers. Ann. Bot. (Lond.) 117:565-583.

da Graça, J.V. and L. Korsten. 2004. Citrus huanglongbing: Review, present status and future strategies, p. 229-245. In: S.A.M.H. Naqvi (ed.). Diseases of fruits and vegetables. Kluwer Academic Publishers, Dordrecht, The Netherlands.

Davis, M., S.N. Mondal, H. Chen, M.E. Rogers, and R.H. Brlansky. 2008. Co-cultivation of 'Candidatus Liberibacter asiaticus' with Actinobacteria from citrus with Huanglongbing. Plant Dis. 92:1547-1550.

Fan, J., C. Chen, Q. Yu, A. Khalaf, D.S. Achor, R.H. Brlansky, G.A. Moore, Z.-G. Li, and F.G. Gmitter, Jr. 2012. Comparative transcriptional and anatomical analysis of tolerant rough lemon and susceptible sweet orange in response to 'Candidatus Liberibacter asiaticus' Infection. Mol. Plant Microbe Interact. 11:1396-1407.

Folimonova, S.Y. and D.S. Achor. 2010. Early events of citrus greening (Huanglongbing) disease development at the ultrastructural level. Phytopathology 100:949-958.

Frost, H.B. and R.K. Soost. 1968. Seed reproduction: Development of gametes and embryos, $\mathrm{p}$. 290-324. In: W. Reuther, L.D. Batchelor, and H.J. Webber (eds.). The citrus industry. Vol. 2. Anatomy, physiology, genetics, and reproduction. Univ. California, Berkeley, CA.

Garnier, M. and J.M. Bové. 1983. Transmission of the organism associated with citrus greening disease from sweet orange to periwinkle by dodder. Phytopathology 73:1358-1363.

Gottwald, T.R. 2010. Current epidemiological understanding of citrus huanglongbing. Annu. Rev. Phytopathol. 48:119-139.

Gulsen, O. and M.L. Roose. 2001. Lemons: Diversity and relationships with selected Citrus genotypes as measured with nuclear genome markers. J. Amer. Soc. Hort. Sci. 126:309-317.

Halbert, S.E. 2005. The discovery of huanglongbing in Florida. In: T.R. Gottwald, W.N. Dixon, J.H. Graham, and P. Berger (eds.). Proceedings of the 2nd International citrus canker and huanglongbing research workshop, Florida Citrus $\mathrm{Mu}-$ tual, Orlando, FL on 7-11 Nov. 2005, Paper H-3.

Halbert, S.E. and K.L. Manjunath. 2004. Asian citrus psyllids (Sternorrhyncha: Psyllidae) and greening disease of citrus: A literature review and assessment of risk in Florida. Fla. Entomol. 87:330-353.

Hall, D.G., M.L. Richardson, E.-D. Ammar, and S.E. Halbert. 2013. Asian citrus psyllid, Diaphorina citri, vector of huanglongbing disease. Entomol. Exp. Appl. 146:207-223. 
Hodgson, R.W. 1967. Horticultural varieties of Citrus, p. 431-587. In: W. Reuther, H.J. Webber, and L.D. Batchelor (eds.). The Citrus Industry volume 1 . Univ. Calif. Press, Berkeley and Los Angeles.

Hussain, M.A. and D. Nath. 1927. The citrus psylla (Diaphorina citri, Kuw.) [Psyllidae: Homoptera]. Memoirs of the Department of Agriculture in India. Entomological Series. 10:5-27.

Jagoueix, S., J.M. Bové, and M. Garnier. 1994. The phloem-limited bacterium of greening disease of the proteobacteria is a member of the alpha subdivision of the proteobacteria. Intl. J. Syst. Bacteriol. 44:379-386.

Koh, E.-J., L. Zhou, D.S. Williams, J. Park, N. Ding, Y.P. Duan, and B.H. Kang. 2012. Callose deposition in the phloem plasmodesmata and inhibition of phloem transport in citrus leaves infected with 'Candidatus Liberibacter asiaticus'. Protoplasma 249:687-697.

Koizumi, M., M. Prommintara, G. Linwattana, and T. Kaisuwan. 1993. Field evaluation of citrus cultivars for greening resistance in Thailand, p. 274-279. In: P. Moreno, J.V. da Graça, and L.W. Timmer (eds.). Proceedings of the 12th Conference of the International Organization of Citrus Virologists (IOCV). University of California, Riverside, CA.

Kumagai, L.B., C.S. LeVesque, C.L. Blomquist, K. Madishetty, Y. Guo, P.W. Woods, S. RooneyLatham, J. Rascoe, T. Gallindo, D. Schnabel, and M. Polek. 2012. First report of Candidatus Liberibacter asiaticus associated with citrus huanglongbing in California. J. Integr. Plant Biol. 58:373-387.

Kunta, M., M. Sétamou, M. Skaria, J. Rascoe, W. Li, M.K. Nakhla, and J.V. da Graça. 2012. First report of citrus huanglongbing in Texas. Phytopathology 102:S4.
Malik, S.K., S. Kumar, I.P. Singh, O.P. Dhariwal, and R. Chaudhury. 2013. Socio-economic importance, domestication trends and in situ conservation of wild Citrus species of Northeast India. Genet. Resources Crop Evol. 60:1655-1671.

Manjunath, K.L., S.E. Halbert, C. Ramadugu, S. Webb, and R.F. Lee. 2008. Detection of 705 'Candidatus Liberibacter asiaticus' in Diaphorina citri and its importance in the management of 706 citrus huanglongbing in Florida. Phytopathology 98:387-396.

Matsumoto, R. and Y. Magano. 2013. Phylogenetic relationships of Citrus and its relatives based on matK gene sequences. PLoS One 8:1-13.

Novelli, V.M., M. Cristofani, A.A. Souza, and M.A. Machado. 2006. Development and characterization of polymorphic microsatellite markers for the sweet orange (Citrus sinensis L. Osbeck). Genet. Mol. Biol. 29:90-96.

Ramadugu, C., M. Keremane, S. Halbert, Y.-P Duan, M.L. Roose, E. Stover, and R. Lee. 2016. Long term field evaluation reveals HLB resistance in Citrus relatives. Plant Dis. 100: $1858-1869$.

Richardson, M.L., C.J. Westbrook, D.G. Hall, E. Stover, Y.P. Duan, and R.F. Lee. 2011. Abundance of citrus leafminer larvae on Citrus and Citrus-related germplasm. HortScience 46: $1260-1264$.

Schneider, H. 1968. Anatomy of greening-diseased sweet orange shoots. Phytopathology 58:11551160.

Sechler, A., E.L. Schuenzel, P. Coke, S. Donnua, N. Thaveechai, E. Postnikova, A.L. Stone, W.L. Schneider, V.D. Damsteegt, and N.W. Schaad. 2009. Cultivation of Candidatus Liberibacter asiaticus, $\mathrm{Ca}$. L. africanus, and $\mathrm{Ca}$. L. americanus associated with huanglongbing. Bacteriology 99:480-486.
Shokrollah, H., T.L. Abdullah, K. Sijam, S.N.A. Abdullah, and N.A.P. Abdullah. 2009. Differential reaction of citrus species in Malaysia to huanglongbing (HLB) disease using grafting method. Amer. J. Agr. Biol. Sci. 4:32-38.

Singerman, A. and P. Useche. 2015. Impact of citrus greening on citrus operations in Florida. Aug. 2016. <http://www.crec.ifas.ufl.edu/ extension/economics/pdf/Impact $\% 20$ Citrus $\%$ 20Greening\%20web.pdf $>$.

Stover, E., S. Inch, M. Richardson, and D.G. Hall. 2016. Conventional citrus of some scion/rootstock combinations show field tolerance under severe huanglongbing disease pressure. HortScience 51:127-132.

Stover, E. and G. McCollum. 2011. Incidence and severity of huanglongbing and Candidatus Liberibacter asiaticus titer among field-infected citrus cultivars. HortScience 46:1344-1348.

Stover, E., G. McCollum, J. Ramos, and R.G. Shatters. 2014. Growth, health and Liberibacter asiaticus titer in diverse citrus scions on mandarin versus trifoliate hybrid rootstocks in a field planting with severe huanglongbing. Proc. Annu. Meet. Fla. State Hort. Soc. 127:53-59.

USDA National Agricultural Statistics Service. 2015. Aug. 2016. <https://www.nass.usda.gov/ Statistics_by_State/Florida/Publications/Citrus/ Citrus_Statistics/2014-15/fcs1415.pdf>.

Wang, Z., Y. Yin, H.H. Hu, Q. Yuan, G. Peng, and Y. Xia. 2006. Development and application of molecular/based diagnosis for 'Candidatus Liberibacter asiaticus', the causal pathogen of citrus huanglongbing. Plant Pathol. 55:630-638.

Westbrook, C.J., D.G. Hall, E. Stover, Y.P. Duan, and R.F. Lee. 2011. Colonization of Citrus and Citrus-related germplasm by Diaphorina citri (Hemiptera: Psyllidae). HortScience 46:9971005. 